\title{
Correction to: Preconditioning with VEGF Enhances Angiogenic and Neuroprotective Effects of Bone Marrow Mononuclear Cell Transplantation in a Rat Model of Chronic Cerebral Hypoperfusion
}

\author{
Jianping Wang ${ }^{1} \cdot$ Xiaojie $\mathrm{Fu}^{1} \cdot$ Lie $\mathrm{Yu}^{1} \cdot \mathrm{Nan} \mathrm{Li}^{1} \cdot$ Menghan Wang ${ }^{1} \cdot \mathrm{Xi} \mathrm{Liu}^{1} \cdot \mathrm{Di}_{\text {Zhang }}{ }^{1} \cdot$ Wei Han ${ }^{1}$. \\ Chenguang Zhou ${ }^{1} \cdot$ Jian Wang ${ }^{2}$ \\ Published online: 30 June 2020 \\ (C) Springer Science+Business Media, LLC, part of Springer Nature 2020
}

\section{Correction to Mol Neurobiol}

https://doi.org/10.1007/s12035-015-9512-8

The original version of this article unfortunately contained a careless error in Fig. $2 \mathrm{~b}-\mathrm{c}$, where the pictures of group Vehicle were the same with group VEGF.

The correct Fig. 2b-c is hereby provided.

This correction does not change the conclusion of this paper.

We are sorry for this error and inconvenience caused.

The online version of the original article can be found at https://oi.org/ $10.1007 / \mathrm{s} 12035-015-9512-8$

\footnotetext{
Jianping Wang

wjpwfy666@126.com

$\triangle$ Jian Wang

jwang79@jhmi.edu
}

1 Department of Neurology, The Fifth Affiliated Hospital of Zhengzhou University, Zhengzhou 450052, Henan, China

2 Department of Anesthesiology/Critical Care Medicine, Johns Hopkins University, School of Medicine, Baltimore, MD, USA 


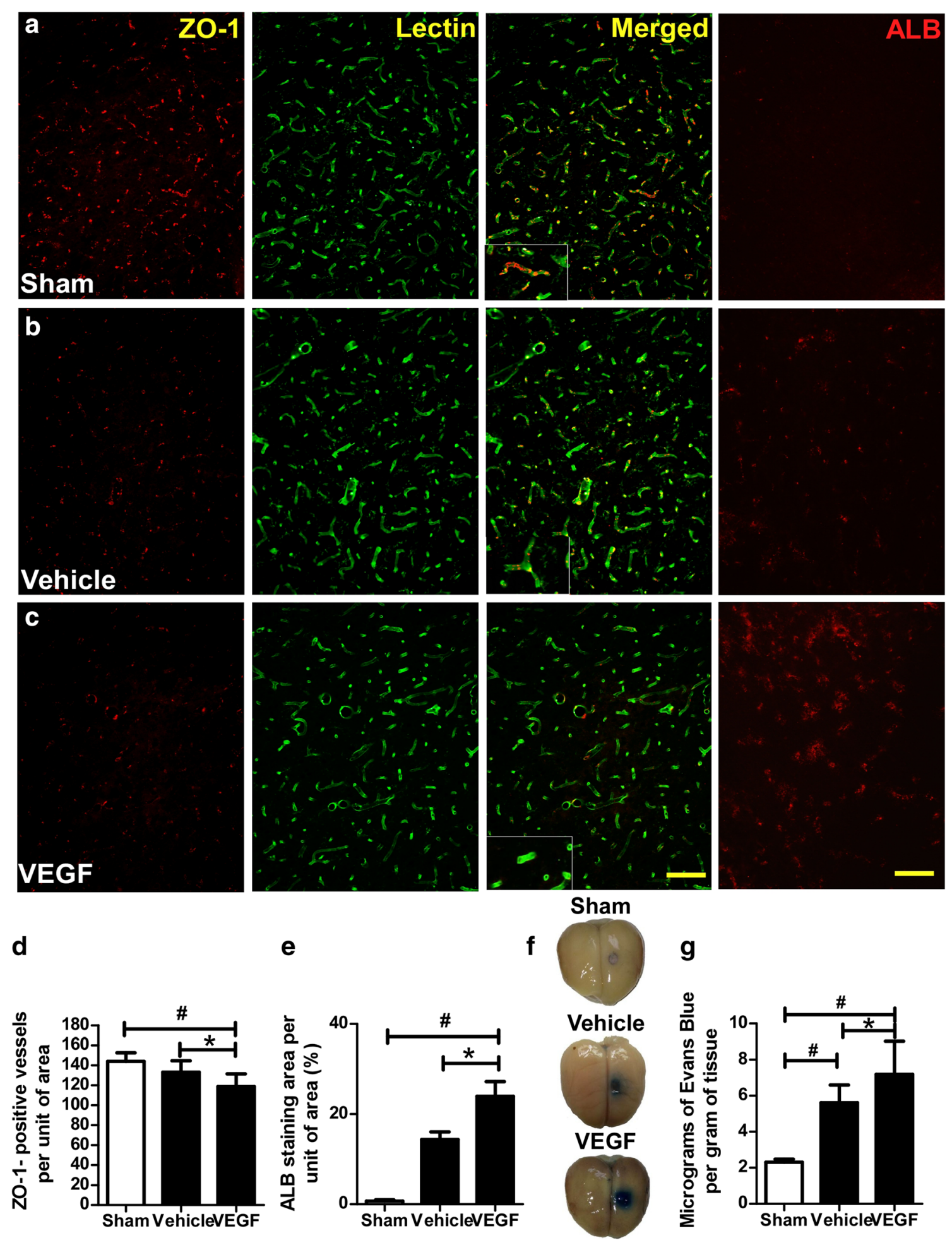

